\title{
Fiesta, quejas y duelos de amor en el imaginario sonoro cervantino: la guitarra, el laúd y la vihuela ${ }^{1}$
}

\author{
Germán LABrador López de AzCOnA*
}

Se ha dicho con razón que la guitarra es el instrumento que más frecuentemente aparece en la obra de Cervantes ${ }^{2}$. Efectivamente, la guitarra está presente en gran parte de las situaciones musicales que imagina el autor, bien como parte fundamental de la fiesta y el bullicio con que terminan varios de los entremeses cervantinos, como confidente de las quejas de amor, como acompañamiento del canto o, en el caso de El celoso extremeño, como figura recurrente e imprescindible, por medio de la habilidad de Loaysa y la afición del criado Luis, cuyo interés por el instrumento se asocia indisolublemente a la propia trama de la novela. Pese a ello, esta vinculación no ha recibido especial atención por parte del mundo académico, siendo como es de gran importancia como elemento caracterizador de situaciones bien definidas ${ }^{3}$ : no

* Universidad Autónoma de Madrid.

1. El presente texto ha sido realizado en el marco del proyecto de investigación El Quijote en la música (siglo XX). Dirección General de Ciencia y Tecnología (2008-2010), ref. HUM-2007-61277/ ARTE.

2. Miguel Querol GavaldÁ, La música en la obra de Cervantes, Barcelona, Comtalia, 1948, p. 138: «El número de veces que Cervantes menciona la guitarra está en relación directa con la popularidad de que gozaba este instrumento. Son tantos los textos cervantinos referentes a la guitarra, que, de ponerlos todos, aun sin comentario alguno, ocuparían algunas páginas». Existe una reedición de este interesante estudio (Centro de Estudios Cervantinos, 2005). Ciertamente, la hipótesis de Querol se ajusta a la realidad, como mostramos en este trabajo.

3. Efectivamente, escasos y parciales son los estudios directamente relacionados con este aspecto de la producción cervantina y/o musical. Únicamente hemos podido documentar los debidos a J. S. MANifold, «Cervantes, the guitar and history», Canon, 1954, 7 (8), pp. 342 y ss.; más recientemente, Pedro Manuel LóPez Gutiérrez, «La música y la guitarra en la obra de Cervantes», Toletum: Boletín de la Real Academia de Bellas Artes y Ciencias Históricas de Toledo, 1995 (segunda época, n. ${ }^{\circ} 33$ ), pp. 69-71, este último una breve introducción a un programa de concierto, en realidad. Pese a ser un 
solo es el medio eficaz de hacer presente el jolgorio y la alegría en el teatro cervantino; en menor medida, el instrumento tiene una participación importante en la caracterización del ambiente campestre en La Gitanilla, El rufián dichoso o La casa de los celos y, finalmente, es un importante elemento que se añade al donaire de Vicente de la Rosa, de Basilio o de don Clavijo, en el Quijote, o del Asturiano, en La ilustre Fregona. Curiosamente, en estos cuatro casos resultaba tan extremado el tañer de los personajes que, más que tocar el instrumento, «hacían hablar» a la guitarra, lo que denota un uso «distinto» de los expuestos anteriormente.

De uno u otro modo, la guitarra aparece en la obra cervantina al menos en cincuenta y dos ocasiones ${ }^{4}$, hasta el punto de llegar a ser el instrumento musical por antonomasia; efectivamente, en El rufián viudo leemos cómo en determinado momento deben entrar «dos músicos, sin guitarras»", observación que, lejos de resultar gratuita, sería necesaria en un contexto en el que se entendía que el «músico» lo era, precisamente, de este instrumento. La misma idea expresa Cervantes en el «Prólogo» a sus Ocho comedias y ocho entremeses nuevos nunca representados, cuando al hablar de la práctica teatral en tiempos de Lope de Rueda explica que

el adorno del teatro era una manta vieja, tirada con dos cordeles de una parte a otra, que hacía lo que llaman vestuario, detrás de la cual estaban los músicos, cantando sin guitarra algún romance antiguo.

A diferencia del tiempo en que escribe el autor (1615), los músicos del teatro cantaban, pero sin guitarra, tal era el estado de abandono en que se hallaban las representaciones teatrales. Pintoresca descripción que llamaría la atención de los lectores del Prólogo, y muestra, junto con los numerosos ejemplos que existen en su producción dramática, de que en la época en que Cervantes escribe lo normal era que la música del teatro tuviera un acompañamiento guitarrístico. Así parece indicarlo también el hecho de que en $L a$ elección de los alcaldes de Daganzo entren «los músicos, de gitanos» ${ }^{6}$ y canten varias veces. Al final del entremés entra un sacristán y se sorprende: «¿Así se rige el pueblo, noramala, entre guitarras, bailes y bureos?», dando a entender que los músicos se habrían acompañado durante toda la obra con este instrumento, aunque Cervantes no lo indica cuando salen a escena. Lo

trabajo de carácter general y basado en una sola obra (aunque con importantes errores de apreciación), es también reseñable por su carácter pionero el artículo de EDGARD IsTEL, «The music in "Don Quixote"», Musical Quarterly, 13, 1927, pp. 434-450, en el que la guitarra es el instrumento más estudiado.

4. La cita literal de cada una de ellas constituye el Anexo que se incluye al final del presente texto, «La guitarra en la obra de Cervantes». El total podría ascender a 58, ya que también recogemos otras seis, incluidas en obras atribuidas en algún momento al escritor.

5. El rufián viudo, acotación posterior al v. 247. Para el presente trabajo citamos por la edición de Florencio Sevilla Arroyo y Antonio Rey Hazas, Obras Completas de Miguel de Cervantes, Alcalá de Henares, C.E.C., 1993-1995. Versión digital de EduARdo UrbinA, Texas A\&M University, Center for the Study of Digital Libraries, 1996-2002.

6. La elección de los alcaldes de Daganzo, acotación previa al v. 258. 
mismo sucede en El juez de los divorcios; al final del entremés el juez pregunta: «Pero, ¿qué es esto? ¿Música y guitarras en mi audiencia?», y seguidamente «entran dos músicos». Como en el caso anterior, Cervantes no especifica con qué deben acompañarse, aunque en ambos casos es lógico suponer que se trate de la guitarra, cuya omisión se explicaría precisamente por ser el instrumento propio de los músicos del teatro.

La elección de la guitarra por el literato es, claramente, un recurso de notable efectividad para caracterizar personajes o, sobre todo, ambientes. Como ocurre en el ejemplo citado de El rufián viudo o en tantos otros del teatro y la novela cervantina, el autor presenta una escena no solo verosímil, sino fácil de imaginar o, en su caso, de ser representada; se muestra, en definitiva, un aspecto de la realidad de la época que sin duda resultaría muy próximo al público por su cotidianeidad. Porque, ¿a qué sonarían las escenas que Cervantes nos muestra en sus entremeses o en sus novelas? ¿Estarían pensando él y sus primeros lectores del siglo XVII en un acompañamiento o en unas armonías tan escogidos como las mismas palabras del escritor? ¿Sería la expresión musical de sus personajes elegante y cultivada, como el mismo lenguaje cervantino?

No nos lo parece. Deliberadamente, Cervantes presenta de modo prácticamente continuo escenas populares, comunes, en las que los personajes tañen guitarras con algarabía y desenfado, «a lo barbero», como se terminaría diciendo $^{7}$. Esto es, se toca «rasgueado», procurando producir una consonancia aceptable en las cuerdas del instrumento, que se hacen sonar simultáneamente. Tal es la acepción con la que fray Juan Bermudo emplea un término parecido, «música golpeada» ${ }^{8}$, que ya será «música ruidosa» para Gaspar Sanz ${ }^{9}$. Con parecida elocuencia se expresa Sebastián de Covarrubias en su Tesoro de la Lengua, al referir como «la guitarra no es más que un cencerro, tan fácil de tañer, especialmente a lo rasgado, que no hay mozo de caballos que no sea músico de guitarra ${ }^{10}$. No resulta extraño, pues, que en Rinconete y Cortadillo uno de los personajes - la Gananciosa - tome una escoba, trasunto de la guitarra, «tan

7. No en vano, el propio hidalgo hace saber, respecto de Maese Nicolás, el barbero, que «todos o los más son guitarristas o copleros». Cfr. Quijote II, 67. La asociación del barbero con el instrumento no solo fue objeto de observación para Cervantes, Quevedo o Góngora. Véase MiguEL QUEROL GAVALDÁ, op. cit., p. 138. Más allá del posible aspecto anecdótico, pronto surgió una expresión, «tocar a lo barbero», que terminó siendo de uso común y que permaneció en la lengua para referirse al modo más sencillo y más extendido de tocar para acompañar la canción o el baile. Así, por ejemplo, FERNANDO FERRANDIERE, Arte de tocar la guitarra española por música, compuesto y ordenado por D. Fernando Ferandiere, Profesor de Música en esta Corte, Madrid, 1792, p. 4, explica como el modo correcto de producir el sonido no es colocando la mano «junto al puente, que es donde comúnmente se rasguea y se toca á lo Barbero». Existe edición facsímil: London, Tecla Editions, 1977.

8. Fray Juan Bermudo, Declaración de instrumentos musicales, Osuna, Juan de León, 1555. Libro cuarto, fol. xcix, v.: «La música que habéis de comenzar a cifrar serán unos villancicos [...] de música golpeada, que comúnmente dan todas las voces juntas». Existe edición facsímil: Madrid, Arte Tripharia, 1982.

9. GASPAR SANZ, Instrucción de música sobre la guitarra española, Zaragoza, Herederos de Diego Dormer, 1674, fol. 8 r. Existe edición facsímil: Zaragoza, Institución Fernando el Católico, 1979.

10. Sebastián de Covarrubias Orozco, Tesoro de la lengua castellana, o española, Madrid, Luis Sánchez, 1611. 
mañera de tocar, tan sin trastes, clavijas ni cuerdas, y tan sin necesidad de templarse», y acompañe con ella la algarabía. Música ruidosa, pues, la de la guitarra... y la de la escoba, fácil de interpretar y propia de los personajes cervantinos $^{11}$; personajes, por otra parte, que normalmente son de humilde extracción o poco favorecidos socialmente, y que resultan caracterizados por el instrumento y su sonido.

De la popularización y la facilidad de tañer este instrumento a lo rasgado da cuenta el desarrollo de un sistema de notación musical apropiado para acompañar los «cantarcillos vulgares» y danzas que constituían el repertorio guitarrístico $^{12}$ : el «abecedario» (fig. n. ${ }^{\circ}$ 1), en el que la música se reduce a la mínima expresión posible, mediante la asociación de determinada letra a una posición de los dedos en el instrumento. De este modo es posible acompañar cualquier baile o tonada, si bien de modo muy elemental (fig. n. ${ }^{\circ}$ 2). Así considerada, la Instrucción de Música de Gaspar Sanz, de donde proceden los ejemplos que aportamos, no es más que una (aunque muy importante) muestra de los numerosos tratados que aparecen, desde el siglo XVII, para enseñar a tocar la guitarra al modo rasgueado, haciendo sonar todas sus cuerdas a un tiempo. Claramente, la efectividad del sistema iba en razón directa de su sencillez.

Figura n. ${ }^{0}$ 1: Ejemplo de «abecedario»,

de la Instrucción de música sobre la guitarra española de Gaspar Sanz (1674)

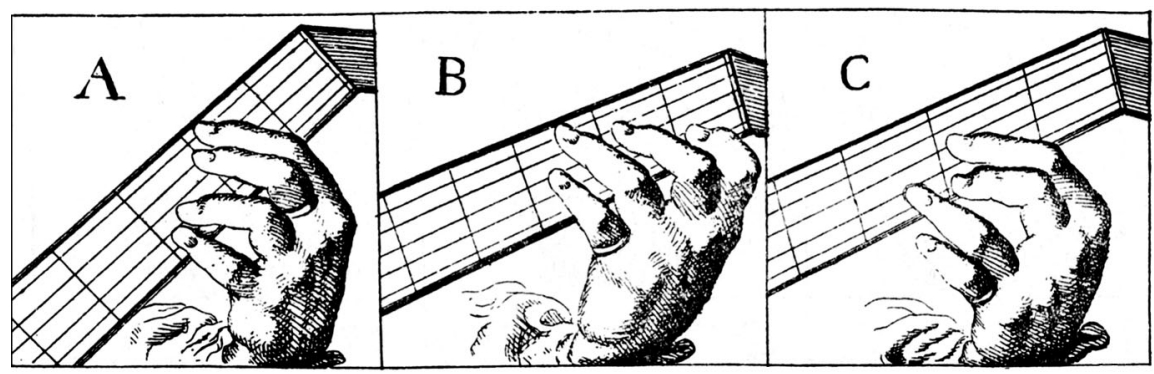

Gaspar Sanz, en el «Abecedario» que incluye en su Instrucción, muestra los rudimentos del arte de acompañar con la guitarra, de modo sencillo y efectivo. Se busca establecer un sistema tal que no sea precisa una instrucción musical avanzada para poder entender cómo tañer el instrumento a fin de acompañar bailes y canciones, rasgueando las cuerdas.

11. Obsérvese el intencionado paralelismo con la guitarra, instrumento que se caracteriza precisamente por tener trastes, clavijas y cuerdas y, significativamente, en palabras del mismo CERVANTES (El celoso extremeño), «el más mañero y menos costoso de los instrumentos».

12. Al respecto del repertorio de los músicos de guitarra, resulta ilustrativo cómo define «tonada» Sebastián de Covarrubias en su Tesoro de la lengua castellana, cit., justamente en la época en que Cervantes da sus obras a la imprenta: «aire de cantarcillo vulgar, cuales son las tonadas que hoy se usan los músicos de guitarra». Así pues, el repertorio del guitarrista eran cantarcillos vulgares, poco sofisticados por su propia naturaleza. 
Figura n. ${ }^{0}$ 2: Dos ejemplos de villano, de la Instrucción de música

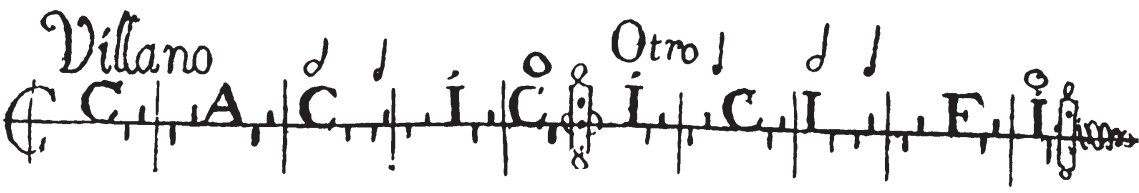

Como aplicación del «Abecedario», para interpretar estos dos ejemplos simplemente se forma la posición correspondiente a cada letra, de acuerdo con las figuras del Abecedario, y se rasguea la guitarra conforme al ritmo indicado mediante los pequeños trazos verticales.

Por otra parte, existe en la época y la sociedad cervantina otro instrumento en el que apenas se ha reparado, posiblemente porque durante mucho tiempo su nombre fue tomado como sinónimo de la guitarra ${ }^{13}$ : la vihuela, propia de algunos de los más grandes músicos del siglo XVI, como Luis de Milán, Narváez, Enríquez de Valderrábano o Fuenllana. Instrumento e instrumentistas coetáneos de Cervantes, que representan una música y un modo muy diferente de tocar; de hecho, en la obra de los vihuelistas aparecen motetes, fragmentos de misas y producciones no destinadas a la diversión popular ni al bullicio. No son tampoco los acompañamientos de sus canciones - algunas sobre textos de Garcilaso, Horacio o Virgilio - de fácil elaboración, ni sencillos de interpretar (fig. n. ${ }^{\circ}$ ). Antes al contrario, diversas voces surgen de la vihuela simultáneamente, cada una con su propósito, con independencia entre sí, conformando un modo de expresión singularmente elaborado y reservado solo a aquellos que se ejercitan con regularidad en su estudio.

Y este es, precisamente, el instrumento reservado a la andante caballería en el Quijote. Es el Caballero de los Espejos el primero que lo tañe, confiándole sus penas de amor, en una situación muy diferente de las ya descritas al respecto de la guitarra ${ }^{14}$ :

\footnotetext{
No quiero yo decir — respondió don Quijote - que ésta sea aventura del todo, sino principio della; que por aquí se comienzan las aventuras. Pero escucha, que, a lo que parece, templando está un laúd o vigüela, y, según escupe y se desembaraza el pecho, debe de prepararse para cantar algo. [...] Replicar quería Sancho a su amo, pero la voz del Caballero del Bosque, que no era muy mala ni muy buena, lo estorbó; y, estando los dos atónitos, oyeron que lo que cantó fue este soneto:

-Dadme, señora, un término que siga,

conforme a vuestra voluntad cortado $[\ldots]$
}

13. A este respecto, resulta muy ilustrativo el artículo de ANTONIO CORONA AlCALDE, «The vihuela and the guitar in sixteenth-century Spain: a critical appraisal of some of the existing evidence», The Lute, XXX, 1990, pp. 2-24. Más allá de la polémica sobre su posible sinonimia y de la realidad organológica de estos instrumentos, en el presente trabajo nos centraremos en sus connotaciones y su sonoridad en la obra cervantina. Claramente, la música «rasgueada» se identifica con la guitarra, mientras que a la vihuela se le asocia con otra sonoridad, otro tipo de música y, finalmente, de intérprete.

14. Quijote II, 12. 
Figura n. ${ }^{0}$ 3: Fragmento del Beatus Ille, de Horacio (Alonso Mudarra, Tres libros de música en cifra para vihuela*)

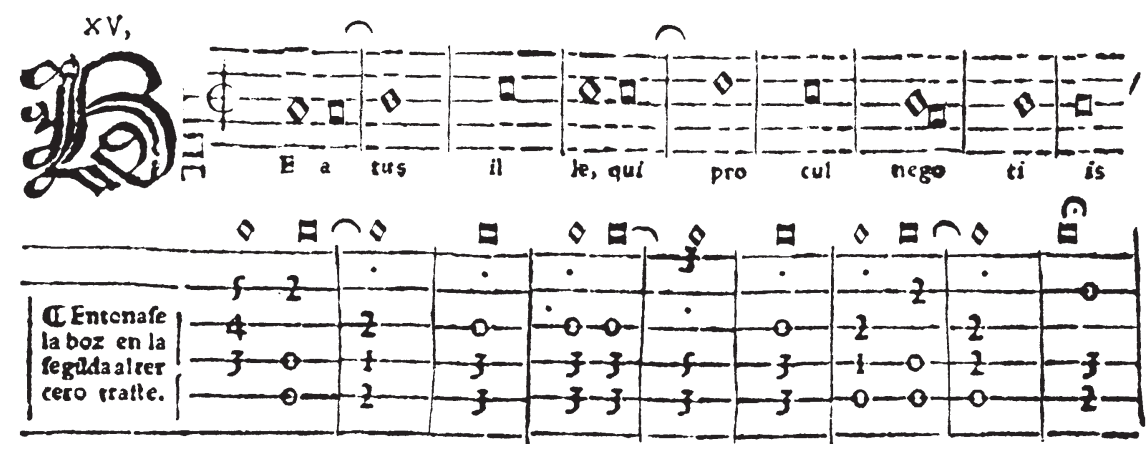

A diferencia de las figuras anteriores, la notación de la música para vihuela resulta más sofisticada, como también lo es su interpretación. En este caso, además de la parte del canto, con el texto poético, se requiere un hexagrama, cada una de cuyas líneas representa una cuerda del instrumento; sobre el hexagrama se disponen diferentes cifras, para indicar qué sonidos corresponden a cada una de las cuerdas. El recurso a textos clásicos, la elaborada escritura de las diferentes voces o la presencia de movimientos de misas polifónicas deja traslucir, por otra parte, el carácter de música elaborada y culta que caracterizó este repertorio.

* Alonso Mudarra, Tres libros de música en cifra para vihuela, Sevilla, Juan de León, 1546.

La segunda y última vez que aparece en la novela es de la mano del propio Alonso Quijano, quien, con motivo de la tristeza de Altisidora, ofrece cantar para consolar a la dama, acompañándose del laúd (o vihuela) ${ }^{15}$ :

Haga vuesa merced, señora, que se me ponga un laúd esta noche en mi aposento, que yo consolaré lo mejor que pudiere a esta lastimada doncella; que en los principios amorosos los desengaños prestos suelen ser remedios calificados.

Y con esto se fue, porque no fuese notado de los que allí le viesen. No se hubo bien apartado, cuando, volviendo en sí la desmayada Altisidora, dijo a su compañera:

- Menester será que se le ponga el laúd, que sin duda don Quijote quiere darnos música, y no será mala, siendo suya.

Poco después se da cuenta del desenlace:

... halló don Quijote una vihuela en su aposento; templóla, abrió la reja, y sintió que andaba gente en el jardín; y, habiendo recorrido los trastes de la vihuela y afinándola lo mejor que supo, escupió y remondóse el pecho, y

15. Quijote II, 46. Obsérvese cómo CERVANTES parece identificar ambos instrumentos tanto aquí como en la anterior cita. 
luego, con una voz ronquilla, aunque entonada, cantó el siguiente romance, que él mismo aquel día había compuesto:

- Suelen las fuerzas de amor

sacar de quicio a las almas,

tomando por instrumento

la ociosidad descuidada.

Instrumento caballeresco, por tanto, y música, por extensión, muy diferente de la que escucharía el resto de los personajes que aparecen en la novela. No deja de resultar llamativo que, por dos veces, Cervantes identifique laúd y vihuela en el Quijote, ya que pese a ser instrumentos de diferente aspecto y sonoridad, obedecen a la misma tradición; también es similar el acercamiento a la música por parte de ambos tipos de instrumentista, pulsando con cada dedo una cuerda, en lugar de «rasgar» (rasguear) todas a la vez, acaso con más entusiasmo que ciencia. Y efectivamente, será el laúd, el laúd barroco, quien mejor recoja esta tradición desde el siglo XVII, con obras incluso de mayor complicación técnica que las de los vihuelistas. De la vihuela, instrumento ya en desuso cuando aparece el Quijote, solo existe otra cita en toda la obra cervantina: en el entremés de La ilustre fregona, al quedar referido cómo Carrizo y Avendaño

al son de la arpa y de una vihuela, con maravillosa voz, oyeron cantar este soneto, que no se le pasó de la memoria a Avendaño:

-Raro, humilde sujeto, que levantas

a tan excelsa cumbre la belleza...

Arpa y vihuela que, caracterizadas en la famosa e imitada clasificación de Cecilio de Roda como «instrumentos aristocráticos» ${ }^{16}$, terminan de situar tanto los instrumentos como el contexto que, de modo tan efectivo, evocan: el del refinamiento, la soledad, el amor... y el del personaje iniciado en un arte minoritario y complejo, en correspondencia con el empleo del soneto. Contexto, versos e instrumentos, por tanto, reservados a personajes aristocráticos, en el mejor sentido. No deja de resultar interesante, por otra parte, el hecho de que la vihuela fuera a principios del siglo XVII un instrumento cuya «edad de oro» ya había pasado, puesto que sus principales autores y repertorio corresponden al siglo $\mathrm{XVI}^{17}$. Se trataba de un instrumento, por tanto, que se entendería vin-

16. CeCilio de RodA, Ilustraciones del Quijote. Los instrumentos músicos y las danzas/Las canciones, Madrid, imp. y litografía de Bernardo Rodríguez, 1905, pp. 13-14. Cecilio de Roda estudia la participación musical en el Quijote, y establece una clasificación de los instrumentos musicales que ha hecho fortuna en los estudios cervantinos: pastoriles, militares, populares y, finalmente (arpa y vihuela), aristocráticos.

17. Sobre las connotaciones a lo refinado y pretérito es interesante recurrir de nuevo a COVARRUBiAs, quien, al referirse a la guitarra en su Tesoro de la lengua, declara que se trata de un «instrumento bien conocido y ejercitado muy en perjuicio de la música que antes se tañía en la vihuela». Así pues, no solo es la vihuela un instrumento en desuso ya en 1611, fecha de la publicación del libro; también es un referente en cuanto a la propia música, que resulta «perjudicada» al popularizarse la guitarra. 
culado a un pasado aún reciente en el momento en que se escribe la novela, antes que parte de la «actualidad musical»; curiosa connotación que termina de situar a la andante caballería en un tiempo pretérito, incluso por un medio tan sutil como el de la música que, raramente, interpretan sus escasos adeptos.

Claramente, Cervantes considera aquí la música no solo como diversión, sino como un tipo de conocimiento propio del caballero andante, pero no de los demás personajes. Con laúd o con vihuela, la sonoridad que cabe asociar a ambos caballeros es muy diferente de la que encontramos en el resto de la novela: música refinada, gobernada por el sentimiento antes que por la pasión, regida por la ciencia y el conocimiento. Es música, también, de recogimiento y no de pública algarabía, de modo que es posible considerarla como elemento caracterizador de determinadas situaciones. En realidad, simplemente atendiendo a las «sonoridades» que el escritor nos presenta, cabe distinguir entre las características de diversiones acaso poco elaboradas, improvisadas normalmente, y las del tañedor experto, con educación musical (y a lo que parece, armado caballero).

Como se ve, Cervantes discierne entre el empleo de la guitarra, propia de los festejos populares o del acompañamiento de bailes y melodías ya entonces tradicionales, como el villano, la zarabanda o el canario y, por otra parte, el empleo de la vihuela o el laúd. Aún más, cabe considerar aquí la existencia no solo de dos instrumentos, sino también de dos tradiciones, de dos modos de tocar... y, en definitiva, de dos tipos de música; de dos ambientes sonoros, en suma. Seguramente es este un aspecto de la obra cervantina por el que el tiempo no ha pasado en balde: de modo muy claro para el lector de la época, la presencia de uno u otro instrumento evocaba con gran eficacia una situación bien caracterizada en sus principales connotaciones (posiblemente ocultas al lector moderno). Con estos antecedentes, no resulta casual que la vihuela aparezca en muy contadas ocasiones y, con ella, un tipo de música, un contexto, refinado y claramente minoritario. Tampoco resulta ajena a la construcción de esta realidad sonora que propone el escritor la utilización del endecasílabo, que contrasta acusadamente con las letrillas encomendadas a la guitarra, en versos de arte menor y rima asonante según se puede apreciar en los ejemplos existentes ${ }^{18}$.

De esta manera, a través de la guitarra y de la vihuela se hace presente en la obra cervantina una importante diferencia, de significante sonoro: la existente entre la música del instrumentista instruido y la del ocasional tañedor ${ }^{19}$; entre la expresión del ideal poético y la expansión festiva; entre, por ser más preci-

18. La relación completa se incluye al final del presente trabajo, aunque no siempre es posible saber qué textos se cantarían; así, en la tercera jornada de Los baños de Argel, Cervantes indica que se interpretarían «los cantares que yo daré». No obstante, en los casos en que existen las canciones, se trata de versos de arte menor y rima asonante, prácticamente siempre romances o romancillos.

19. En este contexto, la vihuela o el laúd son el vehículo apropiado para la «poesía honesta» que Cervantes plantea como cumbre de la creación artística. Al respecto de la poesía honesta y la necesaria destreza que la acompaña, consúltese la interesante aproximación de JUAN JosÉ PASTOR COMíN, El hecho musical en el pensamiento lírico cervantino, Vigo, Academia del Hispanismo, 2007, pp. 87 y ss. 
sos, cultura erudita y cultura popular ${ }^{20}$. Y este, el de la cultura popular, es el medio en el que mayoritariamente se desarrollan las aventuras del caballero, y en realidad la mayor parte de las situaciones que presenta Cervantes a su público $^{21}$.

Con acierto, pues, se ha calificado a esta guitarra cervantina, y no solo metonímicamente, como «vulgar y plebeya», atendiendo no ya a su repertorio, sino especialmente a su público e intérpretes ${ }^{22}$. No solo la referencia que se hacía al principio a la escoba como sucedáneo de la guitarra nos lleva a concluir que el instrumento tiene esta connotación en la obra cervantina; además de las referencias al «tocar rasgueado» y al barbero, en El rufián dichoso, La gran sultana y en Pedro de Urdemalas la guitarra es acompañada por las sonajas, instrumento sin duda poco refinado, y finalmente, en cada uno de los entremeses puede entenderse que los músicos son siempre tañedores de guitarra ${ }^{23}$. Música, por tanto, la de guitarra, destinada a las diversiones populares (vulgares), a lo festivo, al bullicio. Frente a ello, la vihuela (laúd), exponente de una sonoridad muy diferente, propia de música hecha en soledad, es un instrumento que resulta minoritario, sin duda; en cierto sentido, «aristocrático».

Aún es posible apreciar otro sutil matiz en el empleo de estos instrumentos, de la mano de las otras dos apariciones del laúd como instrumento solista que existen en la obra cervantina, ambas en $L a$ Galatea $^{24}$. El instrumento aparece en el Libro II por primera vez; Silerio habla:

Y así, una noche, pensando que ni Timbrio ni otro alguno me escuchaba, por dar alivio un poco al fatigado espíritu, en un retirado aposento, sólo de un laúd acompañado, canté unos versos...

20. Sobre este aspecto volvemos en nuestro «La guitarra y Cervantes: La caracterización de un registro sonoro cervantino propio del siglo XX», Cervantes y El Quijote en la música. Estudios sobre la recepción de un mito, BEGOÑa Lolo (ed.), Madrid, C.E.C.-MEC, 2007, pp. 307-321. En el siglo XVII, como en el XX, la música de guitarra relacionada con Cervantes se desenvuelve, curiosamente, en el mismo medio cultural.

21. No en vano, «los instrumentos que más suenan en el Quijote son toscos y ruidosos, tradicionalmente considerados inferiores e incluso extraños a la literatura y ser de la música». Cfr. ANTONIO García Montalbán, «Lo sonoro, función y símbolo en Don Quijote», Nassarre, XXI, 2005, pp. 389-441.

22. Pedro Manuel López Gutiérrez, op. cit., p. 70. Asimismo, véase la nota 11.

23. La mención al instrumento es explícita en casi todos ellos; en El viejo celoso y El vizcaíno fingido «entran músicos» y se finaliza con música cantada, pero no se indica cómo debe hacerse o con qué instrumento se acompaña. No obstante, véase lo expuesto en la nota 5 al respecto de La elección de los alcaldes de Daganzo y El juez de los divorcios. El caso de El retablo de las maravillas es similar, aunque menos dudoso; al entrar el gobernador junto con otros personajes, aparece también un músico. Poco después, se indica «tocan la zarabanda», lo que mal podría hacerse con instrumentos de percusión. Lo más lógico sería pensar aquí también en una guitarra.

24. Como integrante de un conjunto numeroso, el laúd (laúdes) aparece también más identificado con la vihuela que con la guitarra, en un contexto que parece requerir cierta pericia musical, con un resultado antes de recogimiento que de sonoridades festivas. Tal sucede al aparecer el carro triunfal en el episodio del desencanto de Dulcinea (Quijote II, 35), en el que se oye «agradable música», ejecutada juntamente con chirimías, arpas y laúdes. 
Posteriormente, en el Libro V, será Timbrio el cuitado:

Sólo el descanso que tenía era entretenerme lamentando mis penas, cantándolas o, por mejor decir, llorándolas al son de un laúd de uno de aquellos marineros. Y una noche [...], sentado en el castillo de popa, tomé el laúd y comencé a cantar unos versos que habré de repetir agora, porque se advierta de qué estremo de tristeza y cuán sin pensarlo me pasó la suerte a la mayor alegría que imaginar supiera.

Como en el caso de la vihuela, se canta aquí al amor, pero con un nuevo sentido: se canta también en soledad, si bien con una acentuada tristeza que no se encuentra en las quejas del Caballero del Bosque, del Caballero de los Leones o, finalmente, en el soneto acompañado por el arpa y la vihuela que escuchan Carrizo y Avendaño ${ }^{25}$. Última de las connotaciones que son propias de estos instrumentos en la obra cervantina, la presencia del amor no correspondido, del anhelo por dar salida a este pesar, caracteriza también el empleo del laúd, y presta otro sutil matiz al imaginario sonoro que construye Cervantes.

Llegamos así a la última de las funciones que tiene el instrumento en la obra cervantina, sea vihuela o laúd: la de influir en el ánimo, de modo que no solo se busca conmover o mover las pasiones, sino también remediarlas o, al menos, procurarles alivio ${ }^{26}$. No en vano, recurriendo a las palabras del inmortal caballero, suelen las fuerzas de amor sacar de quicio a las almas. Y el intento de volverlas a su ser, de acordarlas consigo mismas, precisa en el imaginario cervantino del recurso al poder de la música. Pero no de cualquier música, o interpretada de cualquier modo; además del sosiego en que frecuentemente se expresan es necesaria también la poesía, para que surjan así estas canciones en las que sale con la voz el alma.

Alta ocasión, la de componer los ánimos descompuestos, confiada a la canción y a la poesía... y, como requiere Cervantes, a un acompañamiento musical con el instrumento apropiado.

25. También aprecia J. J. REY esta connotación de «alcurnia, soledad y relativa melancolía» en el uso literario de este instrumento durante los siglos de oro. Cfr. «NOMINALIA. Instrumentos musicales en la literatura española desde La Celestina (1499) hasta El Criticón (1651)», I Encuentro Tomás Luis de Victoria y la música española del siglo XVI: Los instrumentos musicales en el siglo XVI, Ávila, Fundación Cultural Santa Teresa, 1997, pp. 41-100, especialmente p. 81.

26. Cfr. José María PAZ GAgo, “"Señora, donde hay música no puede haber cosa mala” ( $D Q$ II, 34). La música en el Quijote», Edad de Oro, XXII, 2003, pp. 361-371. De modo más amplio, referido a la función de la música en general en la novela, Paz Gago apunta esta función de la música, aunque no limitada a determinado instrumento o estado de ánimo. 


\section{Anexo \\ LA GUITARRA EN LA OBRA DE CERVANTES}

Recogiendo el guante que lanzara hace sesenta años Miguel Querol al estudioso de la obra cervantina, y como testimonio de su acertada intuición, se recogen en las páginas que siguen los ejemplos en los que Cervantes hace alusión a la guitarra, con ocasionales y breves indicaciones que aclaran el motivo por el que se cita. Hemos localizado 33 apariciones del instrumento en distintas obras, que unidas a las 19 de El celoso extremeño, entremés en que la guitarra tiene una importancia primordial, suman 52. Asimismo, se incluyen en esta relación tres obras atribuidas en algún momento al escritor, en las que el instrumento aparece otras seis veces, en un contexto, por cierto, muy similar ${ }^{27}$.

Viaje del Parnaso, capítulo segundo, vv. 149 y s.: «es el grande EsPINEL, que en la guitarra / tiene la prima y en el raro estilo». Posteriormente, capítulo octavo, vv. 39-42: «viendo cumplido su deseo / al son de la guitarra mercuriesca / hizo de la Gallarda un gran paseo».

La casa de los celos, jornada segunda, acotación tras el v. 998: «Sale LAUSO, pastor, por una parte de la montaña, con su guitarra, y CoRINTO, por la otra, con otra».

Los baños de Argel, jornada segunda, acotación tras el v. 1309 (Salen Juanico, Francisco, la Señora Catalina, un Cristiano, Costanza, Don Fernando y Julio, «con las guitarras y el rabel»). Asimismo, jornada tercera, acotación tras el v. 2584: «HALIMA con un velo delante del rostro, en lugar de ZARA; llévanla en unas andas en hombros, con música y hachas encendidas, guitarras y voces y grande regocijo, cantando los cantares que yo daré». Poco después, vv. 2882 y s., Osorio se dirige al sacristán: «Pues lleva la guitarra / y, si es posible, vente luego».

El rufián dichoso, acotación tras el v. 555: «Salen DOS Músicos con guitarras, y CRISTÓBAL con su broquel y daga de ganchos». Seguidamente (vv. 565-566), LugO indica: «Vaya agora el guitarresco son, y el aquelindo». Posteriormente, vv. 1687-1689, Doña Ana interviene: «Al campo pienso de ir hoy. / Parece que están templando / una guitarra allí fuera». Finalmente, en la acotación anterior al v. 1744: «Suenan desde lejos guitarras y sonajas...». A continuación, vv. 1744-1745, el PADRE CRUZ se pregunta: «Pero, ¿qué música es esta? ¿Qué guitarras y sonajas...?».

La gran sultana, acotación tras el v. 2084 (Salen los dos Músicos, y MADRIGAL con ellos. Se especifica que «MADRIGAL traiga unas sonajas, y los demás sus guitarras»). Posteriormente, Madrigal se dirige al gran turco, vv. 2162-2164: «¿Qué oficio tiene este? Guitarrista: / quiero decir que tañe una guitarra / peor ochenta veces que su madre»).

La entretenida, v. 2440: el AlgUACIL pregunta «¿Qué guitarra es aquesta?», inquiriendo qué sucede. La connotación aquí no es musical, por tanto.

Pedro de Urdemalas, vv. 1023 y s.: Pascual pide que prosiga la música: «Vuélvanse a repicar esas sonajas, / háganse rajas las guitarras». Más adelante, vv. 2003-2004, mientras BELICA e INÉs bailan, les dice MALDONADO: «El oído en las guitarras y haced azogue los pies». Posteriormente, en la acotación tras el v. 2967: «Suenan guitarras».

27. Para el anexo citamos, como en el texto precedente, por la edición de Florencio SeVILla Arroyo y Antonio Rey Hazas (vid. nota 5). Respecto de las tres obras atribuidas, citamos por la edición de José Manuel Blecua, Miguel de Cervantes. Entremeses, Zaragoza, Ebro, 1976. 
El juez de los divorcios. Al final del entremés, cuando entran en la audiencia los músicos, exclama el juez: «¿Música y guitarras en mi audiencia? ¡Novedad grande es ésta!».

El rufián viudo, acotación tras el v. 247: «Entran dos MúsICos, sin guitarras». Acto seguido, v. 250, Trampagos pregunta, extrañado: « ¿Y las guitarras?». Posteriormente, acotación tras el v. 279: «Vuelve el BARBERO con dos guitarras, y da la una al compañero».

La elección de los alcaldes de Daganzo, vv. 325 y s.: «¿Así se rige el pueblo, noramala, / entre guitarras, bailes y bureos?».

La guarda cuidadosa. Al final del entremés entran los músicos, y dice el amo: «Pues llamen esos oficiales de mi vecino el barbero, para que con sus guitarras y voces nos entremos a celebrar el desposorio, cantando y bailando».

La cueva de Salamanca: "Vuelven a salir el SACRISTÁn [y] el BARBERO, con sus guitarras; Leonarda, Cristina y el Estudiante. Sale el SaCristán con la sotana alzada y ceñida al cuerpo, danzando al son de su misma guitarra».

La Galatea: Libro II: Silerio cuenta cómo «fue que acordé de vestirme como truhán y con una guitarra entrarme en casa de Nísida».

En el Quijote aparece el instrumento en tres ocasiones, vinculado al virtuosismo del tañedor en términos muy similares: Parte I, capítulo LI, al describirse a Vicente de la Rosa: «Añadiósele a estas arrogancias ser un poco músico y tocar una guitarra a lo rasgado, de manera que decían algunos que la hacía hablar». Parte II, capitulo XIX, al presentar a Basilio: "canta como una calandria, y toca una guitarra, que la hace hablar». Finalmente, Capítulo XXXVIII, al referirse a don Clavijo: «tocaba una guitarra que la hacía hablar, y más que era poeta y gran bailarín».

La Gitanilla: "sentándose Andrés sobre un medio alcornoque, pusiéronle en las manos un martillo y unas tenazas, $\mathrm{y}$, al son de dos guitarras que dos gitanos tañían, le hicieron dar dos cabriolas». Más adelante, «Andrés al pie de un alcornoque, Clemente al de una encina, cada uno con una guitarra, convidados del silencio de la noche, [...] cantaron estos versos».

El celoso extremeño: "Cuando Loaysa quería que los que le escuchaban le dejasen, dejaba de cantar y recogía su guitarra, $\mathrm{y}$, acogiéndose a sus muletas, se iba». «Llegándose una noche, como solía, a la puerta, comenzó a templar su guitarra, y sintió que el negro estaba ya atento». Posteriormente, en conversación con el negro Luis, le dice: «En menos de quince días os sacaría tan diestro en la guitarra que pudiésedes tañer sin vergüenza alguna en cualquier esquina [...] apenas habréis comido tres o cuatro moyos de sal, cuando ya os veáis músico corriente y moliente en todo género de guitarra. [...] porque veo ser gran lástima que se pierda una tal voz como la vuestra, faltándole el arrimo de la guitarra; que quiero que sepáis, hermano Luis, que la mejor voz del mundo pierde de sus quilates cuando no se acompaña con el instrumento, ora sea de guitarra o clavicímbano, de órganos o de arpa; pero el que más a vuestra voz le conviene es el instrumento de la guitarra, por ser el más mañero y menos costoso de los instrumentos». Una vez convencido Luis, despide a Loaysa afirmando «que ya me comen los dedos por verlos puestos en la guitarra». El segundo día, «encendió Luis un torzal de cera, y sin más aguardar, sacó su guitarra Loaysa», quien convence a Luis de sus progresos en el instrumento, «y en toda la noche no hizo otra cosa que tañer con la guitarra destemplada». Al llegar la mañana, «el negro arrebató la guitarra y comenzó a to- 
car», de modo que las criadas le preguntan: «De cuándo acá tienes tú guitarra, o quién te la ha dado?». Llegada la noche del siguiente día, Loaysa y Luis «bajaron del pajar, con la guitarra bien encordada», tras lo que «tocando mansamente la guitarra, tales sones hizo Loaysa que causó la admiración de los circunstantes». La siguiente noche, «la banda de las palomas acudió al reclamo de la guitarra». Al franqueársele el paso, «tomó Loaysa la guitarra, y cantó» estremadamente. Finalmente, «la dueña tomó la guitarra, que tenía el negro, y se la puso en las manos a Loaysa, rogándole que la tocase». Tras levantarse el señor de la casa, las mujeres huyen, «dejando solo al músico; al cual, dejando la guitarra y el canto, lleno de turbación, no sabía qué hacerse». Como consecuencia, Luis «se abrazó a su guitarra y se fue a esconder a su pajar [...]; y, con todo esto, no dejaba de tentar las cuerdas de la guitarra».

La ilustre fregona: «El que tocó la guitarra fue el Asturiano [...]. De tal manera tocaba la guitarra Lope, que decían que la hacía hablar».

Entre las obras atribuidas en algún momento a Cervantes, citaremos aquellas en las que también aparece la guitarra ya que, al margen de cuestiones de atribución, sí parece claro que el instrumento es utilizado con las mismas connotaciones y en el mismo contexto:

El hospital de los podridos (entremés): «Y no va muy fuera de camino; porque los tales parecen guitarras de ébano con tapas blancas, y se hacen ahembrados». Al final del mismo entremés, en la acotación que precede a la canción con que se termina la obra, se lee: «Métenle los ministros, y saca VILLAVERDE una guitarra y canta» (seguimos la edición citada de Blecua, respectivamente pp. 123 y 126).

Los Habladores (entremés): «¿Primo dijo vuesa merced? ¡Oh, qué bien que dijo vuesa merced! Primo decimos al hijo del hermano de nuestro padre; primo, a un zapatero de obra prima. Prima es una cuerda de una guitarra. La guitarra se compone de cinco órdenes; las órdenes mendicantes son cuatro...» (seguimos la edición citada de Blecua, p. 106).

La tía fingida (novela): «... y comidos que fueron y no de penos convocaron a sus amigos, juntaron guitarras e instrumentos, previnieron músicos, y fuéronse a un poeta de los que sobran en aquella ciudad...». Poco después, «... juntáronse nueve matantes de la Mancha, que sacaron cualquiera de una taza malagan por sorda que fuese, y cuatro músicos de voz y guitarra, un salterio, una arpa, una bandurria, dos cencerros, y una gaita zamorana, treinta broqueles y otras tantas cotas...» (seguimos la edición citada de Blecua, p. 150). 


\title{
Resumen
}

La importante presencia de la música en la obra de Cervantes tiene, más allá de la caracterización de las situaciones en las que aparece, un significado propio de los instrumentos y de la sonoridad que producen. En el caso de la guitarra, se presentan aquí todas sus apariciones en la obra cervantina, y se muestra el contexto que evoca, muy opuesto al del laúd y la vihuela: música e instrumentos con funciones bien definidas y muy diferente carácter, que reflejan la distancia entre cultura erudita y cultura popular.

Palabras clave: Guitarra. Laúd. Vihuela. Cervantes. Paisaje sonoro. Cultura popular.

Title: Joy, sorrow and love complaints in the Cervantine sonorous imagery: the guitar, the lute and the vihuela.

\begin{abstract}
The importance of music in Cervantes' works has, beyond the characterization of the different situations in which it appears, an important significance: that of the musical instruments and of their particular sonority. In the case of the guitar, all of its appearances in Cervantes' works are presented here, as well as the context that the instrument evokes, very different from that of the lute and vihuela. Music and musical instruments with very clear roles and qualities, both of which reflect the differences between popular culture and that of the elites.
\end{abstract}

Keywords: Guitar. Lute. Vihuela. Cervantes. Sonorous landscape. Popular culture. 